This is a post-peer-review, pre-copyedit version of an article published in Journal of the Association of Nurses in AIDS Care. The final authenticated version is available online at: http://dx.doi.org/10.1016/j.jana.2017.08.006

Nobre, N., Pereira, M., Roine, R. P., Sutinen, J., \& Sintonen, H. (in press). HIV-related self-stigma and healthrelated quality of life of people living with HIV in Finland. Journal of the Association of Nurses in AIDS Care. doi:10.1016/j.jana.2017.08.006

\begin{abstract}
We examined how HIV-related self-stigma was associated with different domains of quality of life (QoL), as measured by the WHOQOL-HIV-Bref, and health-related quality of life (HRQoL) as measured by the generic $15 \mathrm{D}$, to identify the factors associated with self-stigma of people living with HIV (PLWH). The study sample included 440 patients living with HIV followed at the Infectious Disease Clinic of Helsinki University Hospital. Participants with more severe self-stigma reported significantly lower QoL and HRQoL. Male gender, co-habiting with a partner, and disclosure of HIV status were associated with less self-stigma; high education level and financial difficulties were associated with greater self-stigma. Having lived longer with HIV, being unemployed, and living alone were also predictors of self-stigma via financial difficulties. The findings suggest that selfstigma is a complex and multidimensional phenomenon that impacts the HRQoL of PLWH. Psychosocial interventions to enhance the well-being of PLWH are increasingly needed.
\end{abstract}

Keywords: health-related quality of life; HIV; quality of life; stigma; WHOQOL-HIV-Bref; 15D 


\section{HIV-related Self-Stigma and Health-related Quality of Life of People Living with HIV in}

\section{Finland}

Almost 4 decades ago, the world struggled with the emergence of a new disease: HIV infection. Limited knowledge about HIV aroused, in many societies, waves of fear, resulting in notable stigma and discrimination against those who were infected. Remarkably, despite significant advances in the field, fear, denial, stigma, and discrimination are still considerable dilemmas faced by many people living with HIV (PLWH; Helms et al., 2017) and represent a significant obstacle to public health programs (Brent, 2016; Grossman \& Stangl, 2013).

Discussions of stigma have their roots in the classic work of Goffman (1986), who defined stigma as "an attribute that is deeply discrediting" (p. 3) and that, in the eyes of society, serves to discredit the person who experiences it. Goffman (1986) argued that stigmatized individuals were seen as possessing an undesirable difference. In the context of HIV, the undesirable difference lead to a higher level of stigmatization because it was often associated with unsafe sex or drug use or both, which have often been regarded as socially stigmatized behaviors (Ho \& Holloway, 2016). HIVrelated stigma as a social construct may, therefore, be internalized by PLWH.

Manifestations of HIV-related self-stigma include being ashamed, feelings of being dirty or worthless, or fearing others' prejudiced behaviors (Bennett, Traub, Mace, Juarascio, \& O'Hayer, 2016; Helms et al., 2017; Nobre, 2011). Self-stigma stems from the internalization of negative experiences of discrimination and prejudice from others (also known as enacted stigma; Turan et al., 2016), therefore reducing the individual's quality of life (QoL; Charles et al., 2012; FusterRuizdeapodaca, Molero, Holgado, \& Mayordomo, 2014; Holzemer et al., 2009; Slater et al., 2013; Wu et al., 2015).

Stigma and discrimination have also been characterized by a high degree of intercultural diversity and complexity (Heatherton, Kleck, Hebl, \& Hull, 2003; Parker \& Aggleton, 2003). Across multiple cultural settings, HIV-related stigma has been shown to reduce access to HIV testing, medication adherence, seeking support from family or friends, and integration into social networks (e.g., Levy et al., 2014; Mahajan et al., 2008; Valenzuela et al., 2015). These conditions can compromise the QoL of PLWH. Moreover, effects of HIV-related self-stigma on psychological and 
physical well-being (Earnshaw, Smith, Chaudoir, Amico, \& Copenhaver, 2013; Li, Hsieh, Morano, \& Sheng, 2016) and its association with sociodemographic factors (Logie, James, Tharao, \& Loutfy, 2011; Logie \& Gadalla, 2009; Loutfy et al., 2012; Sayles et al., 2008) and health care outcomes (Helms et al., 2017; Slater et al., 2015; Sumari-de Boer, Sprangers, Prins, \& Nieuwkerk, 2012; Turan et al., 2016) have also been studied in recent years across multiple countries. However, the pathways through which self-stigma impacts the health-related quality of life (HRQoL) of PLWH has scarcely been explored.

Finland is a country with low adult HIV prevalence (0.1\%). By June 2017, 3,811 people had ever been diagnosed with HIV in Finland (National Institute for Health and Welfare, 2017). The annual number of newly diagnosed cases has remained stable during the last 10 years. The proportion of immigrants among newly-diagnosed patients has exceeded 50\% during the last 5 years. Medical care for PLWH is provided by infectious disease specialists. Clinics can assist PLWH with social welfare issues and third sector organizations provide peer support and psychological assistance. Clinic visits and antiretroviral treatment are free of charge. The situation in Finland - a combination of a low HIV prevalence and high quality health care - offers an interesting and unique setting in which to study HIV-related stigma. Therefore, the aims of our study were (a) to examine the prevalence of HIV-related self-stigma in Finland; (b) to examine how self-stigma was associated with QoL and HRQoL; and (c) to explore associations between sociodemographic and HIV-related factors, selfstigma, financial difficulties, and HRQoL.

\section{Methods}

\section{Participants and Procedures}

The participants in this cross-sectional study were consecutively recruited from June 2013 to October 2014 from the Infectious Disease Clinic of Helsinki University Hospital, from two HIV support groups (HIV Finland and The Finnish AIDS Council), or from the Helsinki Deaconess Institute. General inclusion criteria were being at least 18 years of age and having a diagnosis of HIV infection. Of the 550 participants invited to participate, 14 refused and 83 failed to return the set of questionnaires (response rate, $82.4 \%$ ). Thirteen participants were further excluded due to missing 
responses to questions related to HIV-related stigma. The final sample was thus comprised of 440 PLWH.

Prior to completing the set of questionnaires, each participant received a full explanation of the objectives of the study and provided written informed consent. The study was approved by Helsinki University Hospital and Helsinki Deaconess Institute, as well as by the two participating HIV support groups.

\section{Measures}

Sociodemographic and HIV-related variables. Sociodemographic data (age, gender, marital status, education, employment status, mode of HIV transmission) were self-reported. Clinical data (HIV stage, CD4+ T-cell count, year of HIV diagnosis, presence of co-morbidities, and combination antiretroviral therapy [cART]) were collected from participant medical records. Financial difficulties were assessed with the following question: To what extent has HIV caused you financial difficulties?, which was rated on a 5-point scale ranging from 1 (not at all) to 5 (very much).

Quality of life. Quality of life was assessed with the Finnish version of the WHOQOL-HIVBref (Nobre, Pereira, Roine, Sutinen, \& Sintonen, 2016). The WHOQOL-HIV-Bref is a 31-item selfreport questionnaire yielding a multidimensional profile of scores across domains and facets (O'Connell \& Skevington, 2012). The WHOQOL-HIV-Bref assesses six domains: physical, psychological, level of independence, social relationships, environment, and spirituality. These domains cover 29 specific facets of one question each. One additional facet ( 2 items) pertains to global QoL and general health. The items are answered on a 5-point response scale in which 1 indicates low QoL and 5 indicates high QoL. All domain scores were transformed to reflect a 0 to 100 scale (higher scores correspond to a better QoL). In this study, Cronbach's alpha of the domains ranged between 0.64 (Spirituality) and 0.84 (Psychological).

Health-related quality of life. HRQoL was measured by the 15D (Sintonen, 1994; 1995). The $15 \mathrm{D}$ is a generic, standardized, self-administered instrument with 15 dimensions (mobility, vision, hearing, breathing, sleeping, eating, speech, excretion, usual activities, mental function, discomfort and symptoms, depression, distress, vitality, and sexual activity). For each dimension, the respondent chose one of the five ordinal levels of severity that best described his/her present state of health $(1=$ 
best, $5=$ worst $)$. The single index score $(15 \mathrm{D}$ score $)$, represented the overall HRQoL on a $0-1$ scale $(1$ $=$ full health, $0=$ being dead), and the dimension level values, reflecting the goodness of the levels relative to no problems on that dimension $(=1)$ and to being dead $(=0)$, were calculated from the health state descriptive system by means of a set of population-based preference or utility weights. In our sample, Cronbach's alpha of the $15 \mathrm{D}$ was 0.86 .

HIV-related self-stigma. Self-stigma was assessed by three questions adapted from the HIV Stigma Scale (Berger, Ferrans, \& Lashley, 2001): Has HIV caused you feelings of guilt?, Has HIV caused you feelings of shame?, and Does having HIV make you feel dirty/ unclean? These questions were rated on a 5-point response scale ranging from 1 (not at all) to 5 (very much). The scores of each question were added together to obtain a final cumulative score ranging from 3 to 15 . Higher scores indicated greater HIV-related self-stigma. Self-stigma scores were also categorized into two groups. No/little self-stigma was defined as scores from 3 to 6; and moderate/severe self-stigma as scores from 7 to 15 . Cronbach's alpha of the self-stigma items was 0.86 .

\section{Data Analysis}

Data were analyzed with the Statistical Package for Social Sciences (IBM SPSS, version 22.0). Chi-square analyses and Student's $t$ tests were conducted to compare the study groups in terms of categorical and continuous variables, respectively. To examine the associations between sociodemographic and HIV-related variables, self-stigma, and HRQoL, we hypothesized, in the light of previous knowledge (see Table 1) and plausible a priori assumptions, a path model with three endogenous variables (self-stigma, financial difficulties, HRQoL), and a set of exogenous sociodemographic variables. Financial difficulties were introduced as a third endogenous variable, given the evidence of the strong negative association of financial difficulties with QoL previously identified in this sample of PLWH (Nobre, Pereira, Roine, Sintonen, \& Sutinen, 2017) and in other chronic conditions (Perrone et al., 2016; Torvinen et al., 2013). To estimate the path co-efficients (standardized beta co-efficients) for the path model, following the recommendations of Boker and McArdle (2014), three stepwise linear regression models were run, one for each endogenous variable, with the exogenous variables as potential explanatory variables plus financial difficulties for selfstigma, and self-stigma and financial difficulties for the 15D score. $P$-values $\leq .05$ were considered 
statistically significant. Table 1 shows the hypothesized directions of the effects of different study variables.

\section{Results}

\section{Participant Characteristics}

The study sample included 440 patients with HIV infection, with a mean age of 47.5 years. Overall, most participants were male (77.2\%), employed (63.3\%), asymptomatic (72.4\%), and had been diagnosed with HIV an average 10.8 years earlier. Regarding self-reported mode of HIV acquisition, men who have sex with men (MSM) accounted for 55\% of HIV diagnoses. At the time of the assessment, a vast majority (94.7\%) of patients were on cART. The existence of medical comorbidities was reported by $59 \%$ of participants; the most common co-morbidities were hypertension (21.4\%), hyperlipidemia (20.5\%), insomnia (17.5\%), depression (14.3\%), hepatitis C (9.7\%), asthma (6.5\%), and diabetes (6.5\%). Regarding HIV-related stigma, $54.1 \%$ of participants reported no or minimal self-stigma (Table 2).

\section{Quality of Life and Health-Related Quality of Life}

Overall, participants reporting moderate/severe self-stigma had lower scores in all the six QoL domains of the WHOQOL-HIV-Bref and in the 15D total score compared to their counterparts reporting no/little self-stigma. Mean scores (SE, standard errors) for the WHOQOL-HIV-Bref domains and the $15 \mathrm{D}$ score are reported in Table 3. Regarding the dimensions of the $15 \mathrm{D}$, those who reported moderate/severe self-stigma scored lower on 8 of 15 dimensions (Figure 1). Specifically, significant differences appeared in the dimensions of excretion $(p<.001)$, usual activities $(p=.002)$, mental function $(p<.001)$, discomfort and symptoms $(p=.010)$, depression $(p<.001)$, distress $(p<$ $.001)$, vitality $(p<.001)$, and sexual activity $(p<.001)$. 


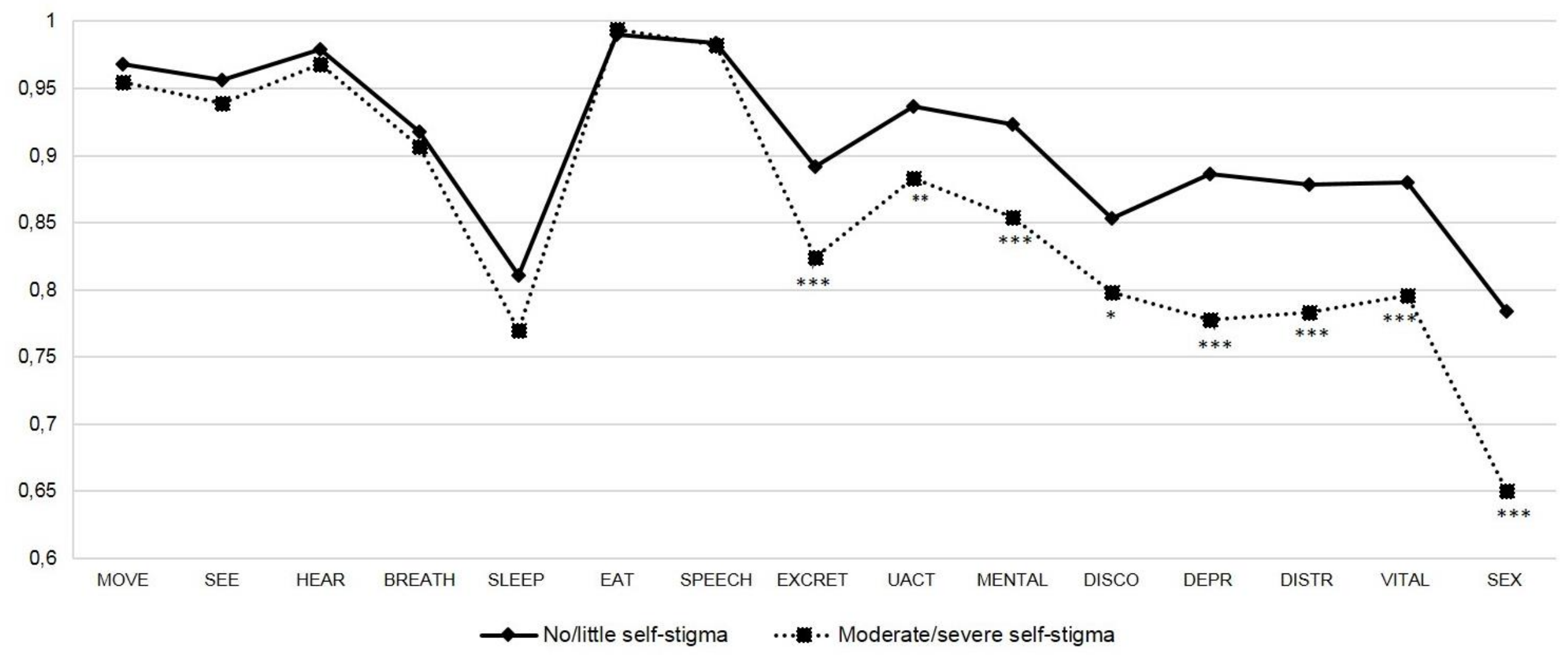

Figure 1. Comparison of 15D dimensions between study groups. $* p<.05 ; * * p<.01 ; * * * p<.001$ 


\section{Path Model}

Apart from high education, being employed, and time since HIV diagnosis, the signs of the coefficients (standardized beta coefficients) of variables explaining the variance of self-stigma emerged as hypothesized. The coefficients of only five variables turned out to be statistically significant. Male gender $(p<.001)$, co-habiting with a partner $(p=.012)$, and disclosure of HIV status $(p=.050)$ were associated with lower self-stigma; high education $(p=.020)$ and financial difficulties $(p=.008)$ were associated with higher self-stigma. The signs of the coefficients of all variables explaining the variance of financial difficulties turned out as expected. Coefficients of only three variables were statistically significant: living alone, having lived longer with an HIV diagnosis, and being unemployed were associated with financial difficulties (all $p<.001$ ). Apart from gender and time since HIV diagnosis, the coefficients of the variables explaining the variance of the $15 \mathrm{D}$ score were as hypothesized. The coefficients of only five variables were statistically significant. Financial difficulties $(p<.001)$, self-stigma $(p<.001)$, and co-morbidities $(p=.001)$ were negatively associated with the 15D score, while co-habiting with a partner $(p=.006)$ and being employed $(p<.001)$ were positively associated (Table 4).

The indirect effect of an exogenous variable on an endogenous variable can be obtained by multiplying the path coefficients of the arrows through another endogenous variable. The total effect can be obtained by summing the direct effect and the indirect effects. For example, the indirect and total effect on the 15D score of co-habiting was calculated as follows: Indirect effect through selfstigma: $-.123 *-.228=.028$; indirect effect through financial difficulties: $-.193 *-.348=.067$; indirect effect through financial difficulties and self-stigma: $-.193 * .127 *-.228=.006$; total indirect effect: .028 $+.067+.006=.101 ;$ total effect: $.101+.110=.211$. These results indicated that male gender and cohabiting had the strongest negative total effects on self-stigma, but high education had the strongest positive effect. Financial difficulties and self-stigma had the strongest negative total effects on the 15D score, and being employed and co-habiting the strongest positive effects (Figure 2). 


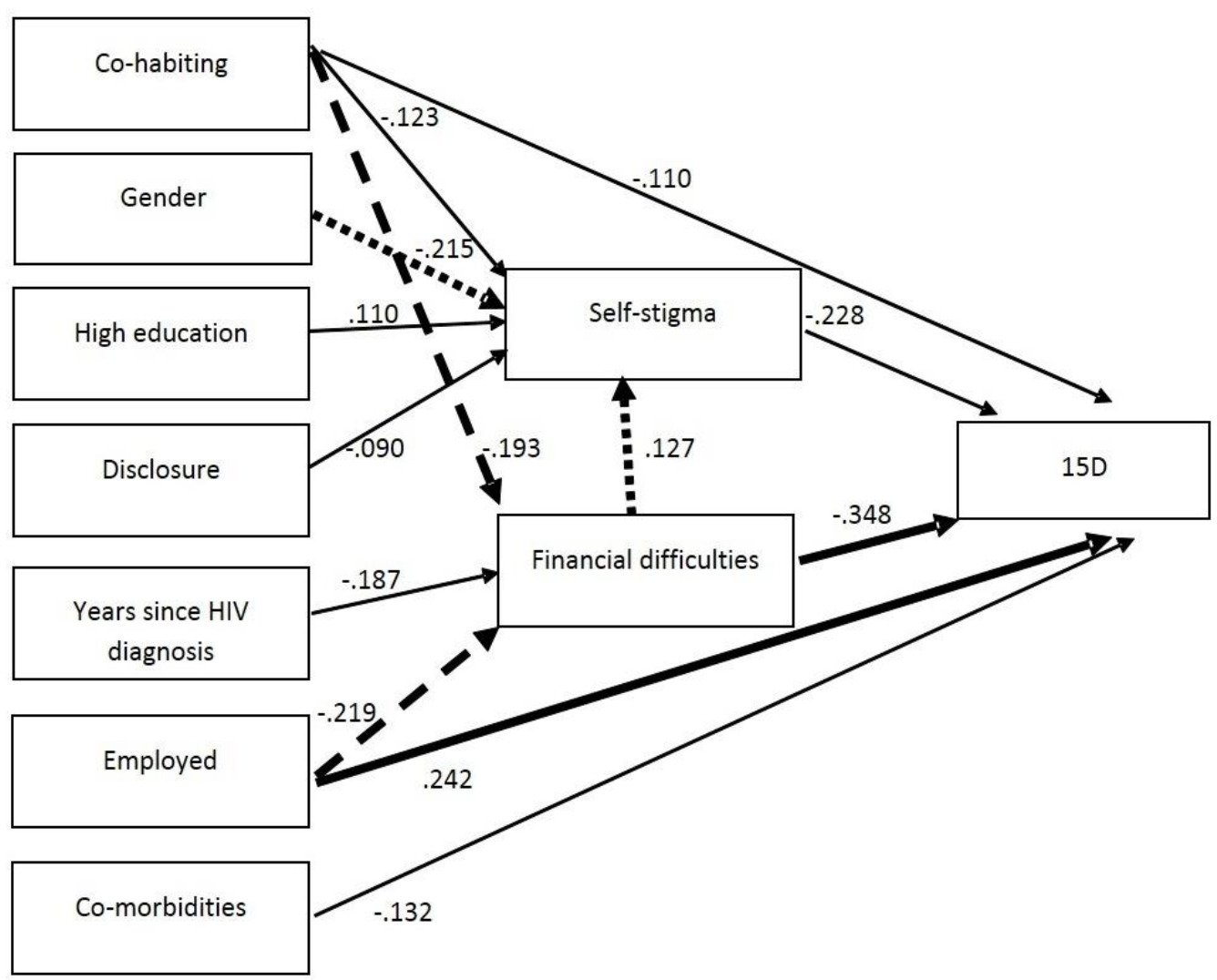

Figure 2. Path model of the sociodemographic and HIV-related variables associated with healthrelated quality of life.

Note: Bold line $=$ strong direct effect on 15D. Financial difficulties and being employed were the strongest predictors of HRQoL of PLWH; bold dotted line = strong direct effect on self-stigma. Gender (female) and financial difficulties were the strongest predictors of self-stigma; bold dashed line $=$ strong direct effect on financial difficulties. Living alone and being unemployed were the strongest predictors of financial difficulties.

\section{Discussion}

In our study, $45.7 \%$ of participants reported moderate/severe forms of self-stigma. Higher levels of self-stigma (moderate/severe) were consistently associated with lower scores on QoL domains and HRQoL. Moreover, considering the total effect of sociodemographic variables, being female, having a higher education, living without a partner, experiencing financial difficulties, and not having disclosed one's HIV status to anyone were independently associated with a stronger experience of self-stigma. Self-stigma itself had a strong negative effect on HRQoL, as measured by the 15D, but the direct effect and total effect of financial difficulties were still stronger. 
Self-stigma has been associated with diminished QoL (e.g., Charles et al., 2012; FusterRuizdeapodaca et al., 2014; Wu et al., 2015). Consistent with previous research, our participants who experienced moderate/severe self-stigma reported significantly reduced QoL in all domains of the WHOQOL-HIV-Bref. Differences were most noticeable in the psychological, social relationships, and spirituality QoL domains. Similar findings were recently reported in a study on Chinese MSM with HIV (Song, Yan, Lin, Wang, \& Wang, 2016), which also found negative associations between stigma and the same QoL domains. The negative impact of self-stigma on social relationships may have reflected potential difficulties that self-stigmatized PLWH experienced within their social networks (friends and family), which may have resulted from the negative experiences of PLWH associated with others' reactions to HIV status disclosure (Chambers et al., 2015; Tsai et al., 2013). Others' negative reactions have played a role in social life withdrawal (Nobre, Kylmä, Kirsi, \& Pereira, 2016). Concealing one's diagnosis from significant others may result in less emotional support (Takada et al., 2014) and increased social isolation (Tsai et al., 2013), negatively impacting the individual's QoL. These negative experiences may lead to further low self-esteem and, accordingly, to significant detriments to psychological well-being (Fuster-Ruizdeapodaca et al., 2014). The association between self-stigma and lower psychological QoL has been widely supported (Charles et al., 2012; Emlet et al., 2013; Fuster-Ruizdeapodaca et al., 2014; Rueda, Law, \& Rourke, 2014) and is reinforced by our findings showing significantly lower scores on all psychological dimensions of the generic 15D among those who reported moderate/severe self-stigma. For PLWH, spirituality has been associated with better ability to cope with HIV stigma stressors. Chaudoir et al. (2012) found that high levels of stigma were attenuated by high levels of spiritual peace. It is, therefore, possible that a high level of spirituality may enhance PLWHs' confidence in the future, as this could foster a comforting sense of life meaning and inner peace, and promote a successful life with HIV (Porter, Brennan-Ing, Burr, Dugan, \& Karpiak, 2017; Rueda et al., 2014).

The path model suggested that women were more likely than men to report increased selfstigma, which was consistent with findings in both higher-(Logie, James, Tharao, \& Loutfy, 2011; Loutfy et al., 2012) and lower-income countries (Geary et al., 2014). Possible explanations may be general social differences between men and women, gender-related social status differences due to 
HIV, and inherent social expectations concerning women in that society (e.g., pregnancy), which may lead to social rejection (Darlington \& Hutson, 2017; Logie et al., 2013; Loutfy et al., 2012). As also noted by Loutfy et al. (2012), our results seem to suggest both sexist and male stereotypical views that may still be associated with HIV, even in a notably equalitarian society such as Finland (World Economic Forum, 2016).

Having a higher education was associated with increased self-stigma. This finding was inconsistent with evidence suggesting that higher education was a protective factor against self-stigma (Coleman, Tate, Gaddist, \& White, 2016; Galvan, Davis, Banks, \& Bing, 2008; Sayles et al., 2008). A possible explanation for this contradiction might be that those with higher education levels may have higher work and social status and, thus, may feel less secure and afraid to disclose their health status for fear of loss of social status and jobs.

As expected, living alone was associated with increased self-stigma. Having a supportive social network was evidently essential for dealing with HIV-enacted stigma and for reducing selfstigma. Hence, emotional support from close networks may mitigate the effects of self-stigma and its development by promoting self-esteem and a sense of belonging to the community (Emlet et al., 2013; Li et al., 2016; Sayles et al., 2008; Takada et al., 2014). Consistent with our prediction, those who had not disclosed their HIV status reported higher levels of self-stigma (Tsai et al., 2013). This was in line with the results of a Finnish study of older adults living with HIV, which indicated that negative past experiences and negative perceptions of others' reactions to HIV disclosure, all lead to selective disclosure patterns (Nobre, 2011). This was a relevant finding, as it may lead to adverse effects, including difficulties in personal relationships and diminished access to social and emotional support. Indeed, Turan et al. (2017) found that perceived negative reactions of the community to disclosure directly impacted internalized stigma. As also noted by Arrey, Bilsen, Lacor, and Deschepper (2015), negative reactions from others, whether experienced, perceived, or internalized, promoted self-stigma and negatively impacted future disclosure, therefore perpetuating a vicious cycle that could compromise an individual's well-being.

The path model also indicated that having lived longer with HIV, being unemployed, and living alone lead to financial difficulties with consequent self-stigma, which, in turn, was associated 
with lower HRQoL. These three factors may have discouraged PLWH from earning a satisfactory income to meet their financial needs, as well as from seeking help from friends, and from social support structures. Increased financial difficulties may lead to more feelings of shame, often resulting from an inability to perform social roles such as engaging in gainful work, particularly noticeable in high-income societies (Sutton, Pemberton, Fahmy, \& Tamiya, 2014). The model, therefore, included not only direct pathways to self-stigma, but also an indirect pathway in which financial difficulties mediate the effects of self-stigma. Further studies using similar path models would be valuable to determine how financial difficulties may affect PLWH, especially those living longer with HIV infection. Future research that expands the proposed model in different cultural settings would also be an interesting contribution.

Limitations imposed by the convenience sample and the cross-sectional study design imply that the generalization of the results to the whole population living with HIV in Finland should be performed with caution. Specifically, although approximately $60 \%$ of all PLWH in Finland have been followed at the Infectious Disease Clinic of Helsinki University Hospital, our findings may not fully represent PLWH outside the Helsinki metropolitan area. Some participants were recruited from social support groups and may have had better social networks and support and, therefore, less stigma and better QoL. Although this may underestimate the level of overall self-stigma found in the study, the number of participants recruited from social support groups was small. Thus, they likely did not compromise the results reported herein. The cross-sectional design prevented any conclusions regarding causal associations between study variables, even if, in the context of the path model, we speak of "effects." Having only three questions from the Berger HIV Stigma Scale to assess selfstigma, as well as our categorization of self-stigma, may have been insufficient to provide a thorough representation of the construct of HIV-related self-stigma. In future studies to confirm our findings, it would be of value to use the complete scale, along with an examination of the potential impact of the various forms of HIV-related stigma.

Our study adds to existing literature the finding that HIV-related stigma and financial difficulties are key factors associated with HRQoL in PLWH in Finland. Moreover, our study advances the current state of knowledge on HIV-related self-stigma and how it impacts the HRQoL of 
PLWH, and provides novel evidence about how sociodemographic and HIV-related factors, selfstigma, and financial difficulties interact with each other and affect HRQoL. Because of potential complex synergy between the factors associated with self-stigma and HRQoL, identifying the diversity of these factors (particularly those that are amenable to change via intervention) may provide a significant avenue toward improving patient well-being. In situations in which these factors are present, the findings reported herein could help health care providers make more effective decisions regarding treatment or psychosocial interventions.

\section{Conclusion}

The model tested in our study allowed us to identify some factors that should be considered in interventions directed toward reducing stigma and discrimination in PLWH, particularly those living without a partner, experiencing financial difficulties, and having no HIV disclosure. The knowledge may enhance understanding of patient problems and aid in provision of more appropriate (psychosocial) care. Indeed, our findings emphasized the importance of strengthening social networks, empowering individuals with knowledge and skills to facilitate HIV disclosure to family members or trusted others, and psychosocial support structures, which may also incorporate economic opportunities, such as job referral, as primary strategies for reducing self-stigma, and, consequently, as relevant paths to improve the HRQoL of PLWH.

\section{Key Considerations}

- HIV-related stigma has a significant negative impact on QoL and HRQoL of PLWH.

- Development of wide sources of social support may reduce self-stigma and positively impact the HRQoL of PLWH.

- Addressing sociodemographic and HIV-related factors associated with self-stigma and its impact on HRQoL should be an integral part of HIV management care.

- Reduction of self-stigma may positively impact behavioral and biomedical outcomes. 


\section{References}

Arrey, A. E., Bilsen, J., Lacor, P., \& Deschepper, R. (2015). "It's my secret": Fear of disclosure among sub-Saharan African migrant women living with HIV/AIDS in Belgium. PLoS ONE, 10(3), e0119653. doi:10.1371/journal.pone.0119653

Bennett, D. S., Traub, K., Mace, L., Juarascio, A., \& O’Hayer, C. V. (2016). Shame among people living with HIV: A literature review. AIDS Care, 28, 87-91. doi:10.1080/09540121.2015.1066749

Berger, B. E., Ferrans, C. E., \& Lashley, F. R. (2001). Measuring stigma in people with HIV: Psychometric assessment of the HIV stigma scale. Research in Nursing \& Health, 24, 518529. doi:10.1002/nur.10011

Boker, S. M., \& McArdle, J. J. (2014). Path analysis and path diagrams. Wiley StatsRef: Statistics Reference Online. doi:10.1002/9781118445112.stat06517

Brent, R. J. (2016). The value of reducing HIV stigma. Social Science \& Medicine, 151, 233-240. doi:10.1016/j.socscimed.2016.01.014

Chambers, L. A., Rueda, S., Baker, D. N., Wilson, M. G., Deutsch, R., Raeifar, E., \& Rourke, S. B. (2015). Stigma, HIV and health: A qualitative synthesis. BMC Public Health, 15, 848. doi:10.1186/s12889-015-2197-0

Charles, B., Jeyaseelan, L., Pandian, A. K., Sam, A. E., Thenmozhi, M., \& Jayaseelan, V. (2012). Association between stigma, depression and quality of life of people living with HIV/AIDS (PLHA) in south India - A community based cross sectional study. BMC Public Health, 12, 463. doi:10.1186/1471-2458-12-463

Chaudoir, S. R., Norton, W. E., Earnshaw, V. A., Moneyham, L., Mugavero, M. J., \& Hiers, K. M. (2012). Coping with HIV stigma: Do proactive coping and spiritual peace buffer the effect of stigma on depression? AIDS and Behavior, 16, 2382-2391. doi:10.1007/s10461-011-0039-3

Coleman, J. D., Tate, A. D., Gaddist, B., \& White, J. (2016). Social determinants of HIV-related stigma in faith-based organizations. American Journal of Public Health, 106, 492-496. doi:10.2105/AJPH.2015.302985

Darlington, C. K., \& Hutson, S. P. (2017). Understanding HIV-related stigma among women in the 
southern United States: A literature review. AIDS and Behavior, 21, 12-26.

doi:10.1007/s10461-016-1504-9

Earnshaw, V. A., Smith, L. R., Chaudoir, S. R., Amico, K. R., \& Copenhaver, M. M. (2013). HIV stigma mechanisms and well-being among PLWH: A test of the HIV stigma framework. AIDS and Behavior, 17, 1785-1795. doi:10.1007/s10461-013-0437-9

Emlet, C. A., Brennan, D. J., Brennenstuhl, S., Rueda, S., Hart, T. A., \& Rourke, S. B. (2013). Protective and risk factors associated with stigma in a population of older adults living with HIV in Ontario, Canada. AIDS Care, 25, 1330-1339. doi:10.1080/09540121.2013.774317

Färkkilä, N., Torvinen, S., Roine, R. P., Sintonen, H., Hänninen, J., Taari, K., \& Saarto, T. (2014). Health-related quality of life among breast, prostate, and colorectal cancer patients with endstage disease. Quality of Life Research, 23, 1387-1394. doi:10.1007/s11136-013-0562-y

Fuster-Ruizdeapodaca, M. J., Molero, F., Holgado, F. P., \& Mayordomo, S. (2014). Enacted and internalized stigma and quality of life among people with HIV: The role of group identity. Quality of Life Research, 23, 1967-1975. doi:10.1007/s11136-014-0653-4

Galvan, F. H., Davis, E. M., Banks, D., \& Bing, E. G. (2008). HIV stigma and social support among African Americans. AIDS Patient Care and STDS, 22, 423-436. doi:10.1089/apc.2007.0169

Geary, C., Parker, W., Rogers, S., Haney, E., Njihia, C., Haile, A., \& Walakira, E. (2014). Gender differences in HIV disclosure, stigma, and perceptions of health. AIDS Care, 26, 1419-1425. doi:10.1080/09540121.2014.921278

Goffman, E. (1986). Stigma: Notes on the management of spoiled identity. New York, NY: Simon \& Schuster.

Grossman, C. I., \& Stangl, A. L. (2013). Global action to reduce HIV stigma and discrimination. Journal of the International AIDS Society, 16(Suppl. 2), 18881 doi:10.7448/IAS.16.3.18881

Heatherton, T. F., Kleck, R. E., Hebl, M. R., \& Hull, J. G. (2003). The social psychology of stigma. New York, NY: Guilford.

Helms, C. B., Turan, J. M., Atkins, G., Kempf, M., Clay, O. J., Raper, J. L., ... Turan, B. (2017). Interpersonal mechanisms contributing to the association between HIV-related internalized stigma and medication adherence. AIDS and Behavior, 21, 238-247. doi:10.1007/s10461-016- 
$1320-2$

Ho, S.-S., \& Holloway, A. (2016). The impact of HIV-related stigma on the lives of HIV-positive women: An integrated literature review. Journal of Clinical Nursing, 25, 8-19. doi:10.1111/jocn.12938

Holzemer, W. L., Human, S., Arudo, J., Rosa, M. E., Hamilton, M. J., Corless, I., ... Willard, S. (2009). Exploring HIV stigma and quality of life for persons living with HIV infection. Journal of the Association of Nurses in AIDS Care, 20, 161-168. doi:10.1016/j.jana.2009.02.002

Koskinen, J., Färkkilä, N., Sintonen, H., Saarto, T., Taari, K., \& Roine, R. P. (2017). Financial difficulties and out-of-pocket payments among breast, prostate and colorectal cancer patients. Manuscript submitted for publication.

Levy, M. E., Wilton, L., Phillips, G., Glick, S. N., Kuo, I., Brewer, R. A., .. Magnus, M. (2014). Understanding structural barriers to accessing HIV testing and prevention services among Black men who have sex with men (BMSM) in the United States. AIDS and Behavior, 18, 972-995. doi:10.1007/s10461-014-0719-x

Li, Z., Hsieh, E., Morano, J. P., \& Sheng, Y. (2016). Exploring HIV-related stigma among HIVinfected men who have sex with men in Beijing, China: A correlation study. AIDS Care, 28, 1394-1401. doi:10.1080/09540121.2016.1179713

Logie, C. H., James, L., Tharao, W., \& Loutfy, M. (2013). Associations between HIV-related stigma, racial discrimination, gender discrimination, and depression among HIV-positive African, Caribbean, and Black women in Ontario, Canada. AIDS Patient Care and STDs, 27, 114-122. doi:10.1089/apc.2012.0296

Logie, C. H., James, L., Tharao, W., \& Loutfy, M. R. (2011). HIV, gender, race, sexual orientation, and sex work: A qualitative study of intersectional stigma experienced by HIV-positive women in Ontario, Canada. PLoS Medicine, 8(11), e1001124. doi:10.1371/journal.pmed.1001124

Logie, C., \& Gadalla, T. M. (2009). Meta-analysis of health and demographic correlates of stigma towards people living with HIV. AIDS Care, 21, 742-753. doi:10.1080/09540120802511877 
Loutfy, M. R., Logie, C. H., Zhang, Y., Blitz, S. L., Margolese, S. L., Tharao, W. E., . . Raboud, J. M. (2012). Gender and ethnicity differences in HIV-related stigma experienced by people living with HIV in Ontario, Canada. PloS One, 7(12), e48168. doi:10.1371/journal.pone. 0048168

Mahajan, A. P., Sayles, J. N., Patel, V. A., Remien, R. H., Ortiz, D., Szekeres, G., \& Coates, T. J. (2008). Stigma in the HIV/AIDS epidemic: A review of the literature and recommendations for the way forward. AIDS, 22(Suppl. 2), S67-S79. doi:10.1097/01.aids.0000327438.13291.62

National Institute for Health and Welfare. (2017). HIV Suomessa [HIV in Finland]. Retrieved from https://www.thl.fi/ttr/gen/rpt/hivsuo.pdf

Nobre, N. (2011). Why? How? and Who? A study on life dynamics and experiences of 50+ people living with HIV/AIDS in Finland (unpublished master's thesis). University of Tampere, Finland.

Nobre, N., Kylmä, J., Kirsi, T. \& Pereira, M. (2016). Social networks of older adults living with HIV in Finland. AIDS Care, 28, 186-190. doi:10.1080/09540121.2015.1071774

Nobre, N., Pereira, M., Roine, R. P, Sutinen, J. \& Sintonen, H. (2016). Are the WHOQOL-HIV-Bref and 15D adequate measures of quality of life in HIV-infected adults? HIV Nursing, 16, 104112.

Nobre, N., Pereira, M., Roine, R. P., Sintonen, H., \& Sutinen, J. (2017). Factors associated with the quality of life of people living with HIV/AIDS in Finland. AIDS Care, 29, 1074-1078. doi:10.1080/09540121.2017.1281879

O'Connell, K. A., \& Skevington, S. M. (2012). An international quality of life instrument to assess wellbeing in adults who are HIV-positive: A short form of the WHOQOL-HIV (31 items). AIDS and Behavior, 16, 452-460. doi:10.1007/s10461-010-9863-0

Parker, R., \& Aggleton, P. (2003). HIV and AIDS-related stigma and discrimination: A conceptual framework and implications for action. Social Science \& Medicine, 57, 13-24. doi:10.1016/S0277-9536(02)00304-0

Perrone, F., Jommi, C., Di Maio, M., Gimigliano, A., Gridelli, C., Pignata, S., ... Bryce, J. (2016). The 
association of financial difficulties with clinical outcomes in cancer patients: Secondary analysis of 16 academic prospective clinical trials conducted in Italy. Annals of Oncology. 27, 2224-2229. doi:10.1093/annonc/mdw433

Porter, K. E., Brennan-Ing, M., Burr, J. A., Dugan, E., \& Karpiak, S. E. (2017). Stigma and psychological well-being among older adults with HIV: The impact of spirituality and integrative health approaches. Gerontologist, 57, 219-228. doi:10.1093/geront/gnv128

Rueda, S., Law S., \& Rourke, S. B. (2014). Psychosocial, mental health, and behavioral issues of aging with HIV. Current Opinion HIV AIDS, 9, 325-331.

doi:10.1097/COH.0000000000000071

Sayles, J., Hays, R., Sarkisian, C., Mahajan, A., Spritzer, K., \& Cunningham, W. (2008).

Development and psychometric assessment of a multidimensional measure of internalized HIV stigma in a sample of HIV-positive adults. AIDS and Behavior, 12, 748-758. doi:10.1007/s10461-008-9375-3

Sintonen, H. (1994). The 15D-measure of health-related quality of life. I. Reliability, validity and sensitivity of its health state descriptive system [Working Paper 41]. Retrieved from http://www.buseco.monash.edu.au/centres/che/pubs/wp41.pdf

Sintonen, H. (1995). The 15D-measure of health-related quality of life. II. Feasibility, reliability and validity of its valuation system. [Working Paper 42]. Retrieved from http://www.buseco.monash.edu.au/centres/che/pubs/wp42.pdf

Slater, L. Z., Moneyham, L., Vance, D. E., Raper, J. L., Mugavero, M. J., \& Childs, G. (2013). Support, stigma, health, coping, and quality of life in older gay men with HIV. Journal of the Association of Nurses in AIDS Care, 24, 38-49. doi:10.1016/j.jana.2012.02.006

Slater, L. Z., Moneyham, L., Vance, D. E., Raper, J. L., Mugavero, M. J., \& Childs, G. (2015). The multiple stigma experience and quality of life in older gay men with HIV. Journal of the Association of Nurses in AIDS Care, 26, 24-35. doi:10.1016/j.jana.2014.06.007

Song, B., Yan, C., Lin, Y., Wang, F., \& Wang, L. (2016). Health-related quality of life in HIVinfected men who have sex with men in China: A cross-sectional study. Medical Science Monitor, 14(22), 2859-2870. doi:10.12659/MSM.897017 
Sumari-de Boer, I. M., Sprangers, M. A., Prins, J. M., \& Nieuwkerk, P. T. (2012). HIV stigma and depressive symptoms are related to adherence and virological response to antiretroviral treatment among immigrant and indigenous HIV infected patients. AIDS and Behavior, 16, 1681-1689. doi:10.1007/s10461-011-0112-y

Sutton, E., Pemberton, S., Fahmy, E., \& Tamiya, Y. (2014). Stigma, shame and the experience of poverty in Japan and the United Kingdom. Social Policy and Society, 13, 143-154. doi:10.1017/S1474746413000419

Takada, S., Weiser, S. D., Kumbakumba, E., Muzoora, C., Martin, J. N., Hunt, P. W., ... Tsai, A. C. (2014). The dynamic relationship between social support and HIV-related stigma in rural Uganda. Annals of Behavioral Medicine, 48, 26-37. doi:10.1007/s12160-013-9576-5

Torvinen, S., Färkkilä, N., Sintonen, H., Saarto, T., Roine, R. P., \& Taari, K. (2013). Health-related quality of life in prostate cancer. Acta Oncologica, 52, 1094-1101. doi:10.3109/0284186X.2012.760848

Tsai, A. C., Bangsberg, D. R., Kegeles, S. M., Katz, I. T., Haberer, J. E., Muzoora, C., ... Weiser, S. D. (2013). Internalized stigma, social distance, and disclosure of HIV seropositivity in rural Uganda. Annals of Behavioral Medicine, 46, 285-294. doi:10.1007/s12160-013-9514-6

Turan, B., Budhwani, H., Fazeli, P. L., Browning, W. R., Raper, J. L., Mugavero, M. J., .. Turan, J. M. (2017). How does stigma affect people living with HIV? The mediating roles of internalized and anticipated HIV stigma in the effects of perceived community stigma on health and psychosocial outcomes. AIDS and Behavior, 21, 283-291. doi:10.1007/s10461$016-1451-5$

Turan, B., Smith, W., Cohen, M. H., Wilson, T. E., Adimora, A. A., Merenstein, D., ... Turan, J. M. (2016). Mechanisms for the negative effects of internalized HIV-related stigma on antiretroviral therapy adherence in women: The mediating roles of social isolation and depression. Journal of Acquired Immune Deficiency Syndromes, 72, 198-205. doi:10.1097/QAI.0000000000000948

Valenzuela, C., Ugarte-Gil, C., Paz, J., Echevarria, J., Gotuzzo, E., Vermund, S. H., \& Kipp A. M. (2015). HIV stigma as a barrier to retention in HIV care at a general hospital in Lima, Peru: A 
case-control study. AIDS and Behavior, 19, 235-245. doi:10.1007/s10461-014-0908-7

World Economic Forum. (2016). The Global Gender Gap Report 2016. Retrieved from http://www3.weforum.org/docs/GGGR16/WEF_Global_Gender_Gap_Report_2016.pdf

Wu, X., Chen, J., Huang, H., Liu, Z., Li, X., \& Wang, H. (2015). Perceived stigma, medical social support and quality of life among people living with HIV/AIDS in Hunan, China. Applied Nursing Research, 28, 169-174. doi:10.1016/j.apnr.2014.09.011 
Table 1

The Hypothesized Directions (+/-) of Direct Effects of Different Variables and the Sources of Hypotheses

\begin{tabular}{|c|c|c|c|}
\hline Variable & Effect on self-stigma & Effect on financial difficulties & Effect of HRQoL (15D score) \\
\hline Co-habiting $(0=$ no, $1=$ yes $)$ & - Sayles et al., 2008 & - Koskinen et al., 2017* & + Färkkilä et al., 2014 \\
\hline Gender $(0=$ female, $1=$ male $)$ & - Loutfy et al., 2012 & + a priori assumption & - Färkkilä et al., 2014 \\
\hline High education $(0=$ female, $1=$ male $)$ & - Sayles et al., 2008 & - Koskinen et al., 2017* & + Färkkilä et al., 2014 \\
\hline Disclosure $(0=$ female, $1=$ male $)$ & - Tsai et al., 2013 & No effect & No effect \\
\hline Years since HIV diagnosis & - Logie \& Gadalla, 2009 & - Koskinen et al., 2017, based on age* & - Koskinen et al., 2017, based on age* \\
\hline Employed $(0=$ female, $1=$ male $)$ & - a priori assumption & - Koskinen et al., 2017* & + Nobre et al., 2017 \\
\hline Co-morbidities $(0=$ female, $1=$ male $)$ & + a priori assumption & + a priori assumption & - Nobre et al., 2017 \\
\hline Financial difficulties & + Logie \& Gadalla, 2009 & NA & - Torvinen et al., 2013 \\
\hline Self-stigma & NNA & Not estimated & - Charles et al., 2012 \\
\hline
\end{tabular}

Note. NA = Not applicable; HRQoL = health-related quality of life; * Personal communication based on an unpublished study. 
Table 2

Sociodemographic and HIV-Related Characteristics of Participants

\begin{tabular}{|c|c|c|c|c|}
\hline & $\begin{array}{l}\text { No stigma } \\
(N=238)\end{array}$ & $\begin{array}{c}\text { Stigma } \\
(N=202)\end{array}$ & $\chi^{2}$ & Cramer's $V$ \\
\hline & $n(\%)$ & $n(\%)$ & & \\
\hline Gender $^{\mathrm{a}}$ & & & $9.90 * *$ & .15 \\
\hline Male & $196(83.1)$ & $140(70.4)$ & & \\
\hline Female & $40(16.9)$ & $59(29.6)$ & & \\
\hline Nationality $^{\mathrm{a}}$ & & & 0.03 & .01 \\
\hline Finnish & $205(86.1)$ & $172(85.6)$ & & \\
\hline Non-Finnish & $33(13.9)$ & $29(14.4)$ & & \\
\hline Employment status ${ }^{\mathrm{a}}$ & & & 2.95 & .08 \\
\hline Employed & $158(66.9)$ & $118(59.0)$ & & \\
\hline Unemployed or not currently working & $78(33.1)$ & $82(41.0)$ & & \\
\hline Education $^{\mathrm{a}}$ & & & 1.79 & .06 \\
\hline$\leq 9$ years & $193(81.8)$ & $173(86.5)$ & & \\
\hline$>9$ years & $43(18.2)$ & $27(13.5)$ & & \\
\hline Marital status $^{\mathrm{a}}$ & & & $10.13^{* *}$ & .15 \\
\hline Single & $75(31.6)$ & $86(43.0)$ & & \\
\hline Married/Registered partnership & $125(52.7)$ & $79(39.5)$ & & \\
\hline Separated/divorced & $31(13.1)$ & $33(16.5)$ & & \\
\hline Widowed & $6(2.5)$ & $2(1.0)$ & & \\
\hline Mode of transmission ${ }^{\mathrm{a}}$ & & & 4.60 & .10 \\
\hline Men who have sex with men & $142(60.2)$ & $100(50.0)$ & & \\
\hline Heterosexual transmission & $69(29.2)$ & $72(36.0)$ & & \\
\hline Intravenous drug use & $13(5.5)$ & $15(7.5)$ & & \\
\hline Blood products/Others/Unknown & $12(5.1)$ & $13(6.5)$ & & \\
\hline Sexual orientation $^{\mathrm{a}}$ & & & 4.04 & .10 \\
\hline Homosexual & $132(56.2)$ & $95(48.0)$ & & \\
\hline Heterosexual & $88(37.4)$ & $93(47.0)$ & & \\
\hline Bisexual & $15(6.4)$ & $10(5.0)$ & & \\
\hline HIV stage ${ }^{a, b}$ & & & 2.56 & .08 \\
\hline Asymptomatic (CDC A) & $165(69.9)$ & $150(75.4)$ & & \\
\hline Symptomatic (CDC B) & $34(14.4)$ & $19(9.5)$ & & \\
\hline AIDS (CDC C) & $37(15.7)$ & $30(15.1)$ & & \\
\hline
\end{tabular}


Last CD4+ T-cell count ${ }^{\mathrm{a}}$

$$
<200 \text { cells } / \mathrm{mm}^{3}
$$$$
201-499 \text { cells } / \mathrm{mm}^{3}
$$$$
>500 \text { cells } / \mathrm{mm}^{3}
$$

On cART $^{\mathrm{a}}$

Yes

No

Co-morbidities ${ }^{\mathrm{a}}$

Yes

No

Disclosure $^{\mathrm{a}}$

Yes

No

\begin{tabular}{l}
\hline \\
\hline Age, years \\
Time since diagnosis, years \\
${ }^{\mathrm{a}}$ \\
Nadir CD4+ T-cell count \\
Last CD4+ T-cell count $^{\mathrm{a}}$
\end{tabular}

$\begin{array}{cc}15(6.4) & 4(2.0) \\ 76(32.3) & 64(32.2) \\ 144(61.3) & 131(65.8)\end{array}$

$5.50 *$ .11

$228(97.0) \quad 183(92.0)$

$7(3.0) \quad 16(8.0)$

1.68

0.6

$132(56.2) \quad 124(62.3)$

$103(43.8) \quad 75(37.7)$

$2.81 \quad .08$

$229(96.2) \quad 187$ (92.6)

$9(3.8) \quad 15(7.4)$

$M(S D) \quad M(S D)$

$\begin{array}{llll}47.5(11.3) & 45.6(11.2) & 1.78 & 0.17\end{array}$

$\begin{array}{llll}10.8(7.2) & 10.33(7.0) & 0.68 & 0.07\end{array}$

265.1(168.3) 261.9(143.3) $\quad 0.21 \quad 0.02$

$590.4(265.4) \quad 626.9(257.5) \quad-1.44 \quad 0.14$

${ }^{a}$ Numbers of patients for different variables do not add up to 440 due to missing values.

${ }^{\mathrm{b}}$ Centers for Disease Control and Prevention (CDC) HIV classification

Note. $* p<.05 ; * * p<.01 ; * * * p<.001$. 
Table 3

Comparison of WHOQOL-HIV-Bref Domains and 15D Score Between Study Groups

\begin{tabular}{|c|c|c|c|c|}
\hline & No Self-Stigma & Self-Stigma & \multirow{2}{*}{$F$} & \multirow{2}{*}{$\eta_{\mathrm{p}}^{2}$} \\
\hline & $M(S E)$ & $M(S E)$ & & \\
\hline \multicolumn{5}{|l|}{ QoL } \\
\hline Physical & $80.60(1.07)$ & $70.53(1.16)$ & $40.74 * * *$ & .09 \\
\hline Psychological & $76.89(1.08)$ & $64.70(1.17)$ & $58.42 * * *$ & .12 \\
\hline Level of Independence & $80.18(1.21)$ & $71.00(1.30)$ & $26.70 * * *$ & .01 \\
\hline Social Relationships & $73.85(1.13)$ & $62.34(1.22)$ & $48.14 * * *$ & .10 \\
\hline Environment & $81.80(0.95)$ & $73.95(1.02)$ & $31.75 * * *$ & .07 \\
\hline Spirituality & $80.10(1.05)$ & 66.78 (1.13) & $74.81 * * *$ & .15 \\
\hline Overall QoL & $75.81(1.18)$ & $64.56(1.28)$ & $41.62 * * *$ & .09 \\
\hline \multicolumn{5}{|l|}{ HRQoL } \\
\hline 15D score & $0.92(0.01)$ & $0.87(0.01)$ & $30.75 * * *$ & .07 \\
\hline
\end{tabular}

Note. $* * * p<.001 ; \mathrm{SE}=$ standard error $; \mathrm{QoL}=$ quality of life $; \mathrm{HRQoL}=$ health-related quality of life. 
Table 4

Direct, Indirect, and Total Effect on Endogenous Variables

\begin{tabular}{|c|c|c|c|c|c|c|c|}
\hline Variables & $\begin{array}{l}\text { Direct effects on } \\
\text { self-stigma }\end{array}$ & $\begin{array}{c}\text { Direct effects on } \\
\text { financial } \\
\text { difficulties }\end{array}$ & $\begin{array}{l}\text { Direct effects on } \\
\text { 15D score }\end{array}$ & $\begin{array}{l}\text { Indirect effects } \\
\text { on self-stigma }\end{array}$ & $\begin{array}{c}\text { Total effects on } \\
\text { self-stigma }\end{array}$ & $\begin{array}{l}\text { Indirect effects } \\
\text { on } 15 \mathrm{D} \text { score }\end{array}$ & $\begin{array}{c}\text { Total effects on } \\
15 \mathrm{D} \text { score }\end{array}$ \\
\hline Gender & $-.215^{* * *}$ & & & & -.215 & .049 & .049 \\
\hline Co-habiting & $-.123 *$ & $-.193 * * *$ & $.110^{* *}$ & -.025 & -.148 & .101 & .211 \\
\hline High education & $.110^{*}$ & & & & .110 & -.025 & -.025 \\
\hline Co-morbidities & & & $-.132 * * *$ & & & & -.132 \\
\hline Years since HIV diagnosis & & $-.187 * * *$ & & -.024 & -.024 & .070 & .070 \\
\hline Employed & & $-.219 * * *$ & $.242 * * *$ & -.028 & -.028 & .082 & .348 \\
\hline Disclosure & $-.090 *$ & & & & -.090 & .021 & .021 \\
\hline Self-stigma & & & $-.228 * * *$ & & & & -.228 \\
\hline Financial difficulties & $.127 * *$ & & $-.348 * * *$ & & .127 & -.029 & -.377 \\
\hline Adj. $R^{2}$ & $.081 * * *$ & $.131^{* * *}$ & $.392 * * *$ & & & & \\
\hline
\end{tabular}

Note. $* p<.05 ; * * p<.01 ; * * * p<.001$. 